\title{
Changes in vegetation and flora of abandoned paddy terraces in responses to drawdown
}

\author{
Mun Gi Hong ${ }^{1}$, Bo Eun Nam ${ }^{1}$ and Jae Geun Kim ${ }^{1,2^{*}}$ (D)
}

\begin{abstract}
In order to assess the impacts of drawdown for land-use change on a Sphagnum-marsh, we compared the vegetation and flora of the wetland before and after the drawdown with focusing on the population of Sphagnum palustre L. Remarkable changes in the coverage of S. palustre and the major vegetational components of the wetland were observed. The coverage of S. palustre markedly decreased by about 75\% (from approx. $247 \mathrm{~m}^{2}$ in 2011 to approx. $62 \mathrm{~m}^{2}$ in 2015) after the drawdown. Tree species such as Salix spp. extended (from about $70 \%$ to about $83 \%$ in the total coverage of the wetland), whereas herbaceous species shrunk after the drawdown. Uplandinhabiting species such as obligate plants for uplands (OBU) increased, whereas wetland-inhabiting species such as facultative plants for wetlands (FACW) and OBW decreased in terms of vegetational coverage. The total number of plant species decreased from 70 species to 62 species after the drawdown, including the disappearance of some wetland-inhabiting species from the wetland. We suggest that the attention for further studies on the abandoned paddy terraces (APTs) and effort for the management and conservation of APTs and APT-inhabiting species that are vulnerable to human-induced disturbances have to be paid more.
\end{abstract}

Keywords: Abandoned paddy fields, Draw-off, Land-use change, Sphagnum palustre

\section{Background}

Wetland plants usually show highly adaptive characteristics under inundated environments such as adventitious root, aerenchyma tissue, dimorphic leaf, and phenotypic plasticity (biomass allocation) (Vretare et al. 2001; Hong and Kim 2016; Moor et al. 2017). On the other hand, despite the fact that some wetland plant species such as Phragmites australis [Cav.] Trin. ex Steud. and Lythrum anceps (Koehne) Makino exhibit high tolerance to dry stress, most wetland plant species are vulnerable to dry condition (Blossey et al. 2001; Hong and Kim 2012; Hong et al. 2018). Thus, drawdown (draw-off) in wetland ecosystems, causing changes in hydrology, may alter wetland vegetation and flora as well (Odland and del Moral 2002). For example, varying water levels and subsequent vegetational differences within abandoned paddy terraces (hereafter APTs) are likely

\footnotetext{
* Correspondence: jaegkim@snu.ac.kr

${ }^{1}$ Department of Biology Education, Seoul National University, Seoul 08826, Republic of Korea

${ }^{2}$ Center for Education Research, Seoul National University, Seoul 08826, Republic of Korea

the results from different drawdown processes within APTs after abandonment (Hong and Kim 2013b; Park et al. 2013). APTs, sometimes, may undergo terrestrialization process due to the severe drawdown for a long period of time (Kirschner et al. 2001; Lee et al. 2002).

Vegetational alterations in wetland ecosystems due to drawdown do not simply mean the shifts in species composition but potential threats for some vulnerable species (Wisheu and Keddy 1991). Desiccation stress by drawdown can be fatal to some vulnerable species particularly in seedling stage (Pence and Clark 2005). For another example, when compared to vascular plant species, wetland bryophytes such as Sphagnum spp. may be more vulnerable to dry stress than vascular plant species because those mosses do not develop cuticle and leaf stomata, which are of importance in preventing water loss (Titus et al. 1983; Schouwenaars and Gosen 2007). Most of all, when the period of drawdown becomes longer, dry stress could cause irreversible damage to Sphagnum spp. and even withering-to-death in the end (Wagner and Titus 1984). 
Thus, many researchers have stressed the importance of management for stable hydrology in wetland ecosystems with considering the conservation of vulnerable species (Byun et al. 2008; Hong et al. 2012; Hong and Kim 2016). Some researchers have noted that stable maintenances of water level in wetland ecosystems seems likely to be much important for some endangered species (Shin et al. 2015; Hong et al. 2018). Nevertheless, numerous studies have reported unintended changes in the vegetation and flora of wetland ecosystems particularly in responses to drawdown (ter Braak and Wiertz 1994; Odland and del Moral 2002). In particular, unexpected changes in vegetation and flora by human activities such as land-use change may lead to the deterioration of wetland ecosystems due to biodiversity loss.

In the present study, we tried to focus on a naturalized Sphagnum-marsh that was once developed as a paddy field within a mountainous area (APTs). In Korea, most of the populations of Sphagnum spp. have been reported in montane wetlands with high altitude of over $1,000 \mathrm{~m}$ asl (Kim 2009; Park and Kim 2012), whereas the study site located in the area with an altitude of about $80 \mathrm{~m}$ asl adjacent to urban areas (Hong and Kim 2013). Recently, the study site has been undergone drawdown for 4 years because of land-use change into a dry field for land-crop production. In order to assess the impacts of drawdown on the Sphagnum-marsh, we compared the vegetation and flora of the wetland before and after the drawdown with focusing on a wetland moss species (Sphagnum palustre L.).

\section{Methods}

The study site $\left(37^{\circ} 17^{\prime} 09.5^{\prime \prime} \mathrm{N}\right.$ and $\left.126^{\circ} 55^{\prime} 20.3^{\prime \prime} \mathrm{E}\right)$ of approximately $3200 \mathrm{~m}^{2}$ in area was located within a mountainous area of Ansan (about $80 \mathrm{~m}$ asl) in Gyeonggi Province, Korea. Mean values of daily mean temperature and monthly precipitation of the study site from 2011 to 2018 were ranged from about $-2{ }^{\circ} \mathrm{C}$ (January) to about $27^{\circ} \mathrm{C}$ (August) and from about $13 \mathrm{~mm}$ (January) to about 380 $\mathrm{mm}$ (July), respectively (Additional file 1: Figure S1). The wetland is a typical APTs consisting of seven wetland units (Hong and Kim 2013a). Inflow water from the watershed of the study site was the major water source and precipitation was the minor one (Hong and Kim 2013a). Diverse plant species (a total of 70 species in 2011) including herbaceous species, tree species such as Salix spp., and a wetland moss species (S. palustre) with mosaic forms were reported from the study site (Hong and Kim 2013a). The inhabitation of an endangered species, scarlet pygmy dragonfly (Nannophya pygmaea Rambur), was also reported from the study site before the drawdown (Hong and Kim 2013a).

In order to exclude possible negative effects of rainy spell in the summer season from the study (Additional file 1: Figure S1), the field surveys for examining water and vegetational characteristics were performed in mid-June 2011 (before) and 2015 (after drawdown). Measuring and sampling water were performed within the area of open water. The values of water depth of each layer (wetland unit) were measured by using a wood-stick ruler $(n=9)$ and averaged. Dissolved oxygen (DO), electric conductivity (EC), and $\mathrm{pH}$ were measured at each sampling spot by using portable meters: DO (Orion 3 Star Portable DO meter; Thermo Fisher Scientific, USA), EC (Corning Checkmate model 311; Corning, USA), and $\mathrm{pH}$ (model AP 63; Fisher, USA). Water samples $(n=11$ in 2011 and $n=6$ in 2015) were carried to the laboratory in Seoul National University and were filtered by using nitrocellulose membrane filter $(0.45 \mu \mathrm{m})$ for chemical analyses. Different numbers of water samples in $2011(n=11)$ and $2015(n=6)$ were due to different areas of inundated fields of the study site between before and after drawdown. Macronutrients $\left(\mathrm{NO}_{3}-\mathrm{N}, \mathrm{NH}_{4}-\mathrm{N}\right.$, and $\left.\mathrm{PO}_{4}-\mathrm{P}\right)$ were analyzed by the hydrazine method (Kamphake et al. 1967), indo-phenol method (Solorzano 1969), and ascorbic acid reduction method (Murphy and Riley 1962), respectively. Cations $\left(\mathrm{K}^{+}, \mathrm{Ca}^{2+}, \mathrm{Na}^{+}\right.$, and $\left.\mathrm{Mg}^{2+}\right)$ as micronutrients were also analyzed by using an atomic absorption spectrometer (Model AA240FS; Varian, USA). To examine possible differences in physicochemical characteristics of wetland water, $t$ test was performed by using statistical software, SPSS package for Windows (IBM SPSS Version 22.0, New York).

In order to estimate the areas of each vegetational cover on the study site, we assumed that each area of the vegetational components could be divided into individual area units $\left(1 \mathrm{~m}^{2}\right.$ in area). To meet the assumption, we divided each vegetational cover into grid-based meshes on the field by using several measuring tapes (50 $\mathrm{m}$ long). The plant species that formed some vegetational patches with less than $1 \mathrm{~m}^{2}$ in area were not included in the vegetational map but in the list of the flora. The taxonomic nomenclature designated by Lee (2003) and the Korean plant names index (KPNI, http:// www.nature.go.kr) were used to identify vascular plant species of the wetland. The classification on plant species into five categories based on the frequency of each species in its habitats (obligate for wetlands (OBW), facultative for wetlands (FACW), facultative (FAC), facultative for uplands (FACU), and obligate for uplands $(\mathrm{OBU})$ ) was performed according to the literature by Choung et al. (2012).

\section{Results and discussion}

Effects of drawdown on water environments and $S$. palustre population

In order to assess the effects of drawdown on water environments and the $S$. palustre population in the study 
site, we compared physicochemical characteristics of wetland water and the coverage of S. palustre in 2011 (before) and 2015 (after drawdown) as the results in responses to environmental changes. Water chemistry of the study site did not show any remarkable change after drawdown. Although both nitrate nitrogen $(0.25 \pm 0.28$ $\mathrm{mg} / \mathrm{L}$ in 2011 and $0.34 \pm 0.08 \mathrm{mg} / \mathrm{L}$ in 2015) and sodium $(5.52 \pm 0.40 \mathrm{mg} / \mathrm{L}$ in 2011 and $6.70 \pm 0.65 \mathrm{mg} / \mathrm{L}$ in 2015$)$ showed small increases with a statistical significance $(p<.05)$ (Additional file 1: Table S1), it would be difficult to consider those differences as meaningful change possibly causing differences in the $S$. palustre population. On the other hand, water depth showed remarkable changes after the drawdown when compared to water chemistry. All the wetland units showed statistically significant decreases in water depth after the drawdown (Fig. 1). In some wetland units, water depth decreased to less than the half level by the drawdown. Although we did not measure the inundated areas within the wetland accurately, it seemed likely that not only the overall water depth but also the area of inundated fields of the wetland markedly decreased simultaneously after the drawdown (Fig. 1).

The coverage of $S$. palustre in the study site markedly decreased by about $75 \%$ (from approx. $247 \mathrm{~m}^{2}$ in 2011 to approx. $62 \mathrm{~m}^{2}$ in 2015) after the drawdown (Fig. 1). In particular, all the S. palustre on the tussock structures of grasses and sedges that had accounted for $73.8 \%$ of the total S. palustre coverage in 2011 clearly disappeared from the wetland. Instead, some dead parts of the moss only remained on the tussock structures. In other words, after the drawdown, the $S$. palustre population remained only on the slope side under the canopy of Pinus densiflora Siebold \& Zucc. in the study site. It appeared that decreases in both water depth and inundated area of the study site might negatively affect the $S$. palustre population by desiccation stress with a long period of time (Wagner and Titus 1984; Hong and Kim 2013c). According to a previous study on the study site (Hong and Kim 2013a), as a hummock species, S. palustre patches were mostly found on the tussock structure with a depth of about $20 \mathrm{~cm}$ and partly on the slope side with a depth of about $5 \mathrm{~cm}$. That is, the sharp decrease in the coverage of S. palustre on the tussock structure does not simply mean the reduction in the horizontal distribution of $S$. palustre only but remarkable reduction in the biomass production of S. palustre population.

\section{Effects of drawdown on vegetation and flora of APTs}

From our study, it seemed likely that a sharp decrease in water depth by drawdown not only reduced the area of S. palustre population but also markedly changed the vegetational map of the wetland (Fig. 2). First of all, the total coverage of tree species increased from about 2235 $\mathrm{m}^{2}$ accounting for about $70 \%$ of the total wetland area in 2011 to about $2643 \mathrm{~m}^{2}$ accounting for about $83 \%$ in

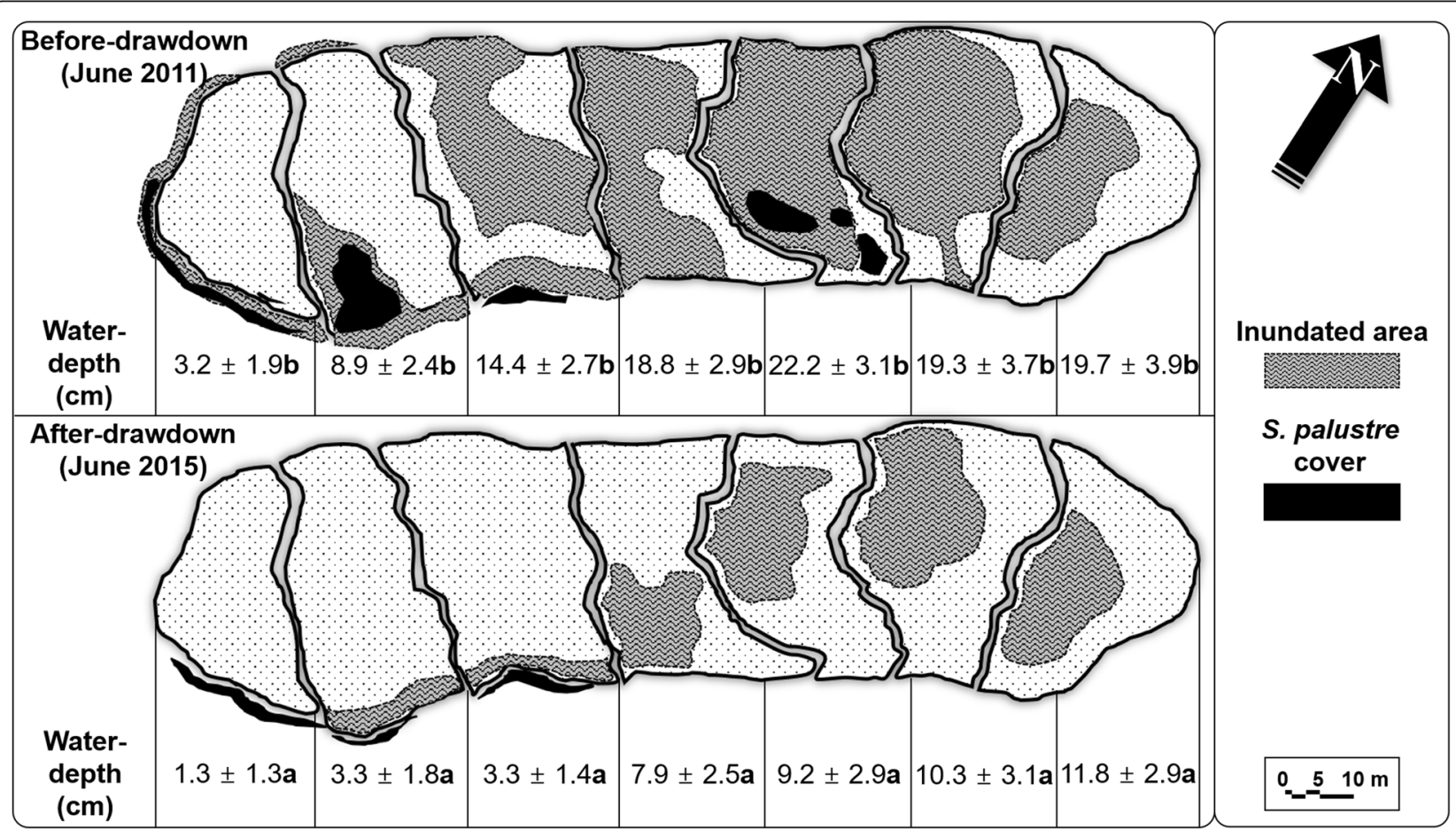

Fig. 1 Inundated areas, S. palustre cover, and water depth of wetland units ( $n=9$, mean \pm 1SD) in 2011 (before) and 2015 (after drawdown). Different alphabets next to water-depth values indicate statistically different sub-groups between 2011 and 2015 by $t$ test $(p<.05)$ 
2015 (Additional file 1: Table S2). For example, Salix pierotii Miq. (from $1203 \mathrm{~m}^{2}$ to $1410 \mathrm{~m}^{2}$ ), S. koriyanagi Miq. (from $189 \mathrm{~m}^{2}$ to $276 \mathrm{~m}^{2}$ ), and Amorpha fruticosa L. (from $388 \mathrm{~m}^{2}$ to $445 \mathrm{~m}^{2}$ ) showed large increases in coverage areas after drawdown (Additional file 1: Table S2). In particular, despite the fact that Rosa multiflora Thunb. is an obligate plant for uplands (OBU), the tree species also showed an increase in the coverage (from $38 \mathrm{~m}^{2}$ to $47 \mathrm{~m}^{2}$ ) within the wetland (Fig. 2).

The occupied areas by tree species within the wetland increased, whereas most of the area of established herbaceous wetland species remarkably decreased after the drawdown. Polygonum thunbergii Siebold \& Zucc. that was the most widely distributed herbaceous species in 2011 showed a sharp decrease in the coverage after the drawdown (from $292 \mathrm{~m}^{2}$ to $94 \mathrm{~m}^{2}$ ). In addition to $P$. thunbergii, some obligate plants for wetlands (OBW) such as Zizania latifolia (Griseb.) Turcz. ex Stapf (from $254 \mathrm{~m}^{2}$ to $175 \mathrm{~m}^{2}$ ), Phragmites australis (Cav.) Trin. ex Steud. (from $123 \mathrm{~m}^{2}$ to $53 \mathrm{~m}^{2}$ ), Carex dickinsii Franch. \& Sav. (from 57 $\mathrm{m}^{2}$ to $29 \mathrm{~m}^{2}$ ), and Scirpus wichurae Boeckeler (from $38 \mathrm{~m}^{2}$ to $16 \mathrm{~m}^{2}$ ) also exhibited remarkable decreases in the coverage (Additional file 1: Table S2). In particular, some herbaceous wetland species such as Leersia japonica (Honda) Honda, Juncus effusus L., and Scirpus karuisawensis Makino were not included as the major vegetational components in 2015 because of decreased areas of their coverages. In contrast, established OBU species such as Mosla dianthera (Buch.-Ham. ex Roxb.) Maxim. did not show any decrease in the coverage and Artemisia princeps Pampanini, rather, showed a small increase in its coverage after the drawdown (Additional file 1: Table S2).

On the other hand, some herbaceous OBU species such as Perilla frutescens (L.) Britton $\left(30 \mathrm{~m}^{2}\right)$, Erigeron annuus (L.) Pers. $\left(23 \mathrm{~m}^{2}\right)$, and Setaria viridis (L.) P. Beauv. $\left(7 \mathrm{~m}^{2}\right)$ newly appeared in 2015 . In addition, two herbaceous species [Echinochloa crus-galli (L.) P. Beauv. and Humulus scandens (Lour.) Merr.] also appeared after the drawdown. Although these species are classified as facultative plants for wetlands (FACW), they are also considered to be the species mainly occurring under environmentally disturbed wetlands (Maun and Barrett 1986; Kim and Kim 2009).

The total number of plant species of the study site slightly decreased from a total of 70 species to 62 species after the drawdown (Additional file 1: Table S3). Although only eight species decreased based on the flora list, it could not be simply considered to be just a reduction in the number of plant species of the study site. Most of all, some FACW [Eclipta prostrata (L.) L., Lobelia chinensis Lour., and Persicaria hydropiper (L.) Delarbre] and an OBW (Eriocaulon parvum Körn.) species disappeared not only in the vegetational map but also in the list of the flora of the study site in 2015.

Hydrological regimes including water depth (level), amplitude, and period are influential factors in determining the characteristics of wetland ecosystems (Carter 1986; Aldous et al. 2005). In particular, water depth as a

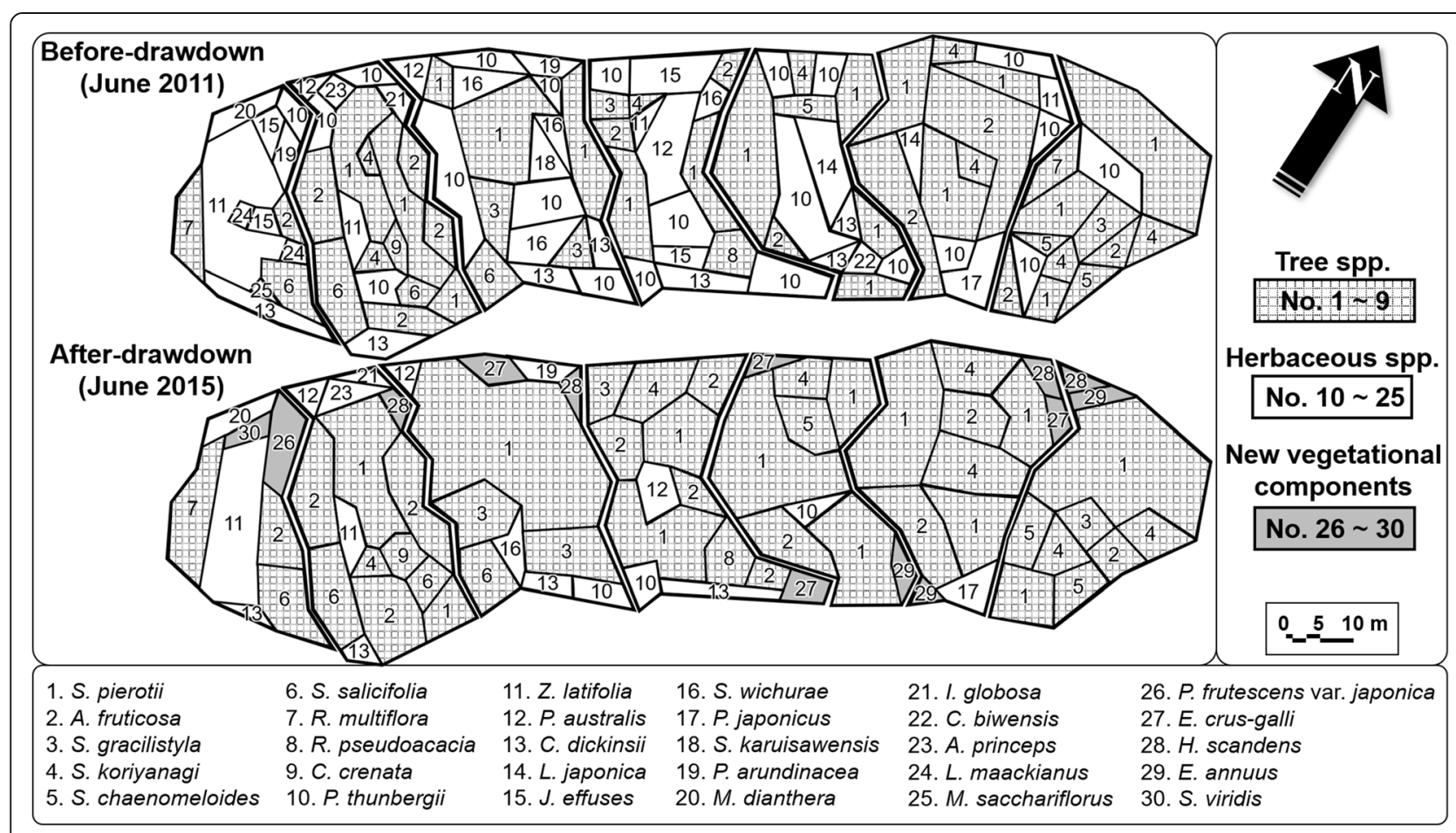

Fig. 2 Vegetation maps of the study site in 2011 (before) and 2015 (after drawdown) 
physical characteristic is known as a critical driver determining the vegetational components of wetland ecosystems (Nam et al. 2014; Byun et al. 2017; Hong et al. 2018). On the other hand, decreases in water depth may alter the vegetational characteristics of wetland ecosystems and even cause terrestrialization (Lee et al. 2002; Byun et al. 2008), which means the transformation of wetlands into upland-like fields (Kirschner et al. 2001).

Such a remarkable alteration in the vegetational components was observed in our study. Tree species extended, whereas herbaceous species shrunk after the drawdown. Upland-inhabiting species such as OBU increased, whereas wetland-inhabiting species such as FACW and OBW decreased in terms of vegetational coverage. Some wetlands-inhabiting species disappeared even after the drawdown. Although we may consider such changes in the study site as a natural process on the trajectory of secondary succession in wetland ecosystems (Shim et al. 2013), it would be more reasonable to see such dramatic alterations as the results by a human-induced disturbance drawdown. In fact, replacement of herbaceous species by tree species often occurs particularly in APTs in which water depth is maintained with low levels or badly maintained (Lee et al. 2002; Byun et al. 2008). On the other hand, it has also been reported that the introduction of tree species such as Salix spp. could be prevented in APTs when deep water condition is maintained (Hong and Kim 2013c; Choi and Kim 2015; Hong et al. 2018).

\section{Implications for APTs and APT-inhabiting species}

According to the private conversation with the landowner of the study site, the wetland was planned to be utilized as a dry field for the production of terrestrial crops after the drawdown process. He also said that there are only few choices that the landowner could choose in practically utilizing such paddy fields within a montane area of low economic value due to low accessibility. Unfortunately, most APTs in Korea are locating in such private lands within mountainous areas (Hong et al. 2012; Park et al. 2013), indicating that those wetlands are also placed under potential threats from human activities such as land-use change as seen in our study site (Uchida and Ushimaru 2014).

During the last several decades, in Japan, high ecological value of APTs as wetland ecosystems has been stressed based on numerous ecological studies particularly on APT-inhabiting rare species including Sphagnum spp. (Uematsu and Ushimaru 2013; Kim et al. 2016; Fukamachi 2017). Based on those ecological studies on APTs, many attempts have been performed for the restoration and conservation of APTs as valuable biotopes (Washitani 2007; Nishio et al. 2017). On the other hand, in Korea, not only the wetland inventory for
APTs in a national scale but also the ecological study on those wetlands are lacking yet. In the case of our study site, despite the fact that the inhabitation of an endangered species (N. pygmaea) was once reported before (Hong and Kim 2013a), unfortunately, the Sphagnum-marsh has been undergone drawdown due to land-use change resulting in decreases in herbaceous wetland species such as $J$. effusus that is essential for the endangered dragonfly species (Yoon et al. 2010).

In addition to the endangered dragonfly species in the study site, the remarkable decrease in the cover of $S$. palustre population after the drawdown might also be another ecological problem that we have to consider seriously. Sphagnum spp. are known as more vulnerable than vascular plant species to human-induced threats such as eutrophication and desiccation so that many countries have already designated some vulnerable Sphagnum spp. as rare species (Andrus et al. 1992; Terracciano et al. 2012). On the other hand, in Korea, Sphagnum spp. have not received much attention by researchers yet. Some studies on the taxonomic classification (Choi et al. 1989) and distributional characteristics (Kim 2009; Paik 2010; Park and Kim 2012; Hong and Kim 2013a; Kim and Kim 2014) of Sphagnum spp. of Korea have been performed only. In particular, the ecological study on Sphagnum spp. is still lacking. Hong and Kim (2013c) reported only a case study on an artificial wetland for guaranteeing the inhabitation of $S$. palustre with other macrophytes in lowlands.

In Korea, it appeared that APTs and APT-inhabiting vulnerable species such as rare plant species and Sphagnum spp. are placed under blind spots in terms of research, management, and conservation yet. We strongly suggest that the attention for further ecological studies and effort for the management and conservation of APTs and APT-inhabiting species that are vulnerable to human-induced disturbances have to be paid more. As naturalized wetlands, it has been noted that APTs show characteristics as both natural (hydrology and biology) (Park et al. 2013) and artificial wetlands (structure and topography) (Katoh et al. 2009; Nam et al. 2018). In that respect, existing APTs may play ecologically important roles as alternatives to artificial wetlands in various ways. In other words, restoration (or reclamation) and following conservation on existing APTs would be more cost-effective and ecologically appropriate instead of constructing more artificial wetlands particularly as biotopes.

\section{Additional file}

Additional file 1: Figure S1. Precipitation (mean $\pm 1 \mathrm{SD}$ ) and temperature (mean \pm 1SE) of the study site from 2011 to 2018. Table S1. Water characteristics of the study site in 2011 (before) and 2015 (after 
drawdown). Boldface letters indicate significant difference between the two years in $t$ test at $p<0.05$ range. Table S2. Differences in the area of vegetational components between in 2011 (before) and 2015 (after drawdown). Table S3. The flora of the study site in 2011 (before) and 2015 (after drawdown). (DOCX 75 kb)

\section{Abbreviations}

APTs: Abandoned paddy terraces; FAC: Facultative; FACU: Facultative for uplands; FACW: Facultative for wetlands; OBU: Obligate for uplands; OBW: Obligate for wetlands

\section{Acknowledgments}

Not applicable

\section{Funding}

This research was supported by the National Research Foundation of Korea (NRF) funded by the Ministry of Education (NRF-2015R1D1A1A01057373) and by the Korea government (MSIT) (NRF-2018R1A2B2002267).

\section{Availability of data and materials}

The datasets during and/or analyzed during the current study are available from the corresponding author on reasonable request.

\section{Author's contributions}

MGH participated in the design of the study, field survey, and data analyses and wrote the manuscript draft. BEN participated in the field survey and data analyses and edited the manuscript draft. JGK conceived the study, participated in the design of study, edited the manuscript draft, and secured the funding. All authors read and approved the final manuscript.

\section{Authors' information}

Not applicable

\section{Ethics approval and consent to participate}

Not applicable

\section{Consent for publication}

Not applicable

\section{Competing interests}

The authors declare that they have no competing interests.

\section{Publisher's Note}

Springer Nature remains neutral with regard to jurisdictional claims in published maps and institutional affiliations.

Received: 29 March 2019 Accepted: 1 May 2019

Published online: 22 May 2019

\section{References}

Aldous A, McCormick P, Ferguson C, Graham S, Craft C. Hydrologic regime controls soil phosphorus fluxes in restoration and undisturbed wetlands. Restor Ecol. 2005:13(2):341-7.

Andrus RE, Karlin EF, Talbot SS. Rare and endangered Sphagnum species in North America. Biol Conserv. 1992;59(2-3):247-54

Blossey B, Skinner LC, Taylor J. Impact and management of purple loosestrife (Lythrum salicaria) in North America. Biodivers Conserv. 2001;10(10):1787-807.

ter Braak CJF, Wiertz J. On the statistical analysis of vegetation change: a wetland affected by water extraction and soil acidification. J Veg Sci. 1994;5(3):361-72.

Byun C, Kwon GJ, Lee D, Wojdak JM, Kim JG. Ecological assessment of plant succession and water quality in abandoned rice fields. J Ecol Field Biol. 2008; 31(3):213-23.

Byun C, Nam JM, Kim JG. Effects of flooding regime on wetland plant growth and species dominance in a mesocosm experiment. Plant Ecol. 2017;218(5): 517-27.

Carter V. An overview of the hydrologic concerns related to wetlands in the United States. Can J Bot. 1986;64(2):364-74.

Choi DM, Lee KO, Lee JY. Study on the general survey of the Korean Sphagnum. Rep Sci Edu. 1989;21:55-81.
Choi H, Kim JG. Study on characteristics of seed germination and seedling growth in Salix gracilistyla for invasive species management. J Korean Environ Res Technol. 2015;18(3):79-95.

Choung YS, Lee WJ, Jo KH, Joo GY, Min BM, Hyun JO, Lee GS. Categorizing vascular plant species occurring in wetland ecosystems of the Korean peninsula. Chuncheon: center for aquatic ecosystem restoration; 2012.

Fukamachi K. Sustainability of terraced paddy fields in traditional satoyama landscapes of Japan. J Environ Manag. 2017;202(3):543-9.

Hong MG, Kim JG. Growth characteristics of cutting culms sectioned at different positions from three reed population. J Korean Soc Environ Res Technol. 2012;15(1):53-62.

Hong MG, Kim JG. Inhabitation characteristics of Sphagnum palustre in abandoned paddy terrace wetland: a case report in Ansan. J Wetl Res. 2013a;15(1):71-8.

Hong MG, Kim JG. Geomorphological characteristics and plant species distribution at abandoned paddy terraces. Korean J Nat Conserv. 2013b;11(3-4):139-49.

Hong MG, Kim JG. A case report on the constructed wetland for the growth of Sphagnum palustre. J Korean Soc Env Res Technol. 2013c;16(6):93-107.

Hong MG, Kim JG. Effects of initial density, nutrient, and water level regime on the seedling survival and growth of Typha orientalis Presl. J Plant Biol. 2016; 59(4):369-76

Hong MG, Nam JM, Kim JG. Occupational strategy of runner reed (Phragmites japonica Steud.): change of growth patterns with developmental aging. Aquat Bot. 2012;97(1):30-4.

Hong MG, Park HJ, Nam BE, Kim JG. Control of runner reed (Phragmites japonicus) in lentic wetlands. J Ecol Environ. 2018;42:18

Kamphake LJ, Hannah SA, Cohen JM. Automated analysis for nitrate by hydrazine reduction. Water Res. 1967;1:205-16.

Katoh K, Sakai S, Takahashi T. Factors maintaining species diversity in satoyama, a traditional agricultural landscape of Japan. Biol Conserv. 2009;142(9):1930-6.

Kim JG. Ecological characteristics of Sphagnum fens in Mt. Odae: I. Sowhangbyungsan-neup. J Korean Wetl Soc. 2009;11(1):15-27.

Kim S, Kim JG. Humulus japonicus accelerates the decomposition of Miscanthus sacchariflorus and Phragmites australis in a floodplain. J Plant Biol. 2009;52: 466-74.

Kim S, Lee S, McCormick M, Kim JG, Kang H. Microbial community and greenhouse gas fluxes from abandoned rice paddies with different vegetation. Microb Ecol. 2016;72(3):692-703.

Kim SK, Kim HY. A survey of weeds occurrence on paddy fields in Gyeongbuk Province of Korea. Weed Turf Sci. 2014;3(1):6-12.

Kirschner AKT, Riegl B, Velimirov B. Degradation of emergent and submerged macrophytesin an oxbow lake of an embanked backwater system: implications for the terrestrialization process. Hydrobiology. 2001;86(4-5): $555-71$.

Lee CS, You YH, Robinson GR. Secondary succession and natural habitat restoration in abandoned paddy fields of central Korea. Restor Ecol. 2002 10(2):306-14

Lee TB. Colored flora of Korea. Seoul: Hyangmunsa; 2003.

Maun MA, Barrett SCH. The biology of Canadian weeds: 77. Echinochloa crus-galli (L.) Beauv. Can J Plant Sci. 1986:66(3):739-59.

Moor H, Rydin H, Hylander K, Nilsson MB, Lindborg R, Norberg J. Towards a traitbased ecology of wetland vegetation. J Ecol. 2017;105(6):1623-35.

Murphy J, Riley JP. A modified single solution method for the determination of phosphate in natural waters. Anal Chem Acta. 1962;27:31-6.

Nam BE, Kim JG, Hong MG. Vegetation and water characteristics of an ecotechnological water purifying biotope in Yongin. J Wetl Res. 2018;20(4): 432-45.

Nam JM, Jeon SH, Choi H, Kim JG. Effects of micro-topography on vegetation pattern in Dunchon-dong wetland. J Wetl Res. 2014;16(4):353-62.

Nishio M, Edu K, Yamazaki Y. Paddy management for potential conservation of endangered Itasenpara bitterling via zooplankton abundance. Agric Ecosyst Environ. 2017;247:166-71

Odland A, del Moral R. Thirteen years of wetland vegetation succession following a permanent drawdown, Myrkdalen Lake. Norway Plant Ecol. 2002;162(2): 185-98.

Paik WK. Vegetation of wetland in Mueido (Incheon-city). Korean J Plant Res. 2010;23(2):197-205

Park J, Hong MG, Kim JG. Relationship between early development of plant community and environmental condition in abandoned paddy terraces at mountainous valleys in Korea. J Ecol Environ. 2013;36:131-40.

Park JH, Kim JG. Ecological characteristics of Sphagnum fens in Mt. Odae: 2 Conservation area of Jilmoe-neup. J Wetl Res. 2012;14(1):101-20. 
Pence VC, Clark JR. Desiccation, cryopreservation and germination of seeds of the rare wetland species, Plantago cordata Lam. Seed Sci Technol. 2005;33(3): 767-70.

Schouwenaars JM, Gosen AM. The sensitivity of Sphagnum to surface layer conditions in a re-wetted bog: a simulation study of water stress. Mires Peat. 2007:2:1-19.

Shim IS, Kim JB, Cho KJ. Syntaxonomical characteristics of abandoned paddy fields by seral stages in South Korea. Korean J Environ Agr. 2013;32(3):185-92.

Shin CJ, Nam JM, Kim JG. Floating mat as a habitat of Cicuta virosa, a vulnerable hydrophyte. Landsc Ecol Eng. 2015;11(1):111-7.

Solorzano L. Determination of ammonia in natural waters by the phenolhypochlorite method. Limnol Oceanogr. 1969;14(5):799-801.

Terracciano S, Giordano S, Bonini I, Miserere L, Spagnuolo V. Genetic variation and structure in endangered populations of Sphangum palustre L. in Italy: a molecular approach to evaluate threats and survival ability. Botany. 2012; 90(10):966-75.

Titus JE, Wagner DJ, Stephens MD. Contrasting water relations of photosynthesis for two Sphagnum mosses. Ecology. 1983;64(5):1 109-15.

Uchida K, Ushimaru A. Biodiversity declines due to abandonment and intensification of agricultural lands: patterns and mechanisms. Ecol Monogr. 2014;84(4):637-58.

Uematsu Y, Ushimaru A. Topography- and management-mediated resource gradients maintain rare and common plant diversity around paddy terraces. Ecol Appl. 2013;23(6):1357-66.

Vretare V, Weisner SEB, Strand JA, Graneli W. Phenotypic plasticity in Phragmites australis as a functional response to water depth. Aquat Bot. 2001:69(2-4): $127-45$.

Wagner DJ, Titus JE. Comparative desiccation tolerance of two Sphagnum mosses. Oecologia. 1984;62(2):182-7.

Washitani I. Restoration of biologically-diverse floodplain wetlands including paddy fields. Glob Environ Res. 2007;11(2):135

Wisheu IC, Keddy PA. Seed banks of a rare wetland plant community: distribution patterns and effects of human-induced disturbance. J Veg Sci. 1991;2(2):181-8.

Yoon J, Nam JM, Kim H, Bae YJ, Kim JG. Nannophya pygmaea (Odonata: Libellulidae), an endangered dragonfly in Korea, prefers abandoned paddy fields in the early seral stage. Environ Entomol. 2010;39(2):278-285(8).

Ready to submit your research? Choose BMC and benefit from:

- fast, convenient online submission

- thorough peer review by experienced researchers in your field

- rapid publication on acceptance

- support for research data, including large and complex data types

- gold Open Access which fosters wider collaboration and increased citations

- maximum visibility for your research: over $100 \mathrm{M}$ website views per year

At $\mathrm{BMC}$, research is always in progress.

Learn more biomedcentral.com/submissions 